\title{
Predictors of biologic-free disease control in patients with rheumatoid arthritis after stopping tumor necrosis factor inhibitor treatment
}

Marjan Ghiti Moghadam,2, Femke B. G. Lamers-Karnebeek ${ }^{3}$, Harald E. Vonkeman ${ }^{1,2}$, Peter M. ten Klooster ${ }^{2^{*}}$ (D, Janneke Tekstra ${ }^{4}$, Barbara van Schaeybroeck ${ }^{5}$, Ruth Klaasen ${ }^{6}$, Marieke van Onna $^{7}$, Hein J. Bernelot Moens ${ }^{8}$, Henk Visser ${ }^{9}$, Annemarie M. Schilder ${ }^{10}$, Marc R. Kok ${ }^{11}$, Robert B. M. Landewé ${ }^{7}$, Piet L. C. M. van Riel ${ }^{12}$, Mart A. F. J. van de Laar ${ }^{1,2}$, Tim L. Jansen ${ }^{13}$ and on behalf of the Dutch National POET Collaboration

\begin{abstract}
Background: The aim of this study was to identify predictors of prolonged disease control after discontinuation of tumor necrosis factor inhibitor (TNFi) treatment in patients with rheumatoid arthritis (RA).

Methods: Post-hoc analysis of 439 RA patients (67.3\% rheumatoid factor positive) with longstanding RA in remission or with stable low disease activity, randomized to stopping TNFi treatment in the multicenter POET trial. Prolonged acceptable disease control was defined as not restarting TNFi treatment within 12 months after stopping. Baseline demographic and disease-related variables were included in univariate and multivariate logistic regression analysis for identifying predictors of relapse.
\end{abstract}

Results: One year after baseline, 220 patients (50.1\%) had not restarted TNFi treatment. Use of an anti-TNF monoclonal antibody (versus a receptor antagonist, $\mathrm{OR}=2.41$; $95 \% \mathrm{Cl}: 1.58-3.67)$, $\leq 10 \mathrm{yrs}$. disease duration (OR=2.15; 95\% Cl: $1.42-$ 3.26) and low or moderate multi-biomarker disease activity (MBDA) scores ( $\mathrm{OR}=2.00$; 95\% Cl: 1.10-3.64) at baseline were independently predictive of successful TNFi discontinuation (area under the receiver operating characteristic curve $=0.66$; 95\% Cl: 0.61-0.71). Results were similar when using no physician-reported flare as the criterion. TNFi-free survival was significantly different for patient groups based on the number of predictors present, ranging from $21.4 \%$ of patients with no predictor present to $66.7 \%$ of patients with all three predictors present.

Conclusion: Patients using an anti-TNF monoclonal antibody, with shorter disease duration and low or moderate baseline MBDA score are most likely to achieve prolonged disease control after TNFi discontinuation.

Trial registration: Netherlands Trial Register NTR3112, 21 October 2011.

Keywords: Rheumatoid arthritis, Remission, Low disease activity, TNFi discontinuation, Predictors

\footnotetext{
* Correspondence: p.m.tenklooster@utwente.nl

${ }^{2}$ Department of Psychology, Health \& Technology, University of Twente, PO

BOX 217, 7500 AE Enschede, the Netherlands

Full list of author information is available at the end of the article
}

(c) The Author(s). 2019 Open Access This article is distributed under the terms of the Creative Commons Attribution 4.0 International License (http://creativecommons.org/licenses/by/4.0/), which permits unrestricted use, distribution, and reproduction in any medium, provided you give appropriate credit to the original author(s) and the source, provide a link to the Creative Commons license, and indicate if changes were made. The Creative Commons Public Domain Dedication waiver (http://creativecommons.org/publicdomain/zero/1.0/) applies to the data made available in this article, unless otherwise stated. 


\section{Background}

Treatment options and outcomes in rheumatoid arthritis (RA) have improved markedly over the last decades [1-3]. Particularly the use of conventional synthetic disease modifying anti-rheumatic drug (csDMARDs) in combination with the more expensive biological agents (bDMARDs such as tumor necrosis factor inhibitors (TNFi) has been shown to be effective in reducing disease activity, improving physical function, and slowing radiographic damage [4-6]. In practice, patients achieving low disease activity (LDA) or even remission usually continue this combination therapy permanently. This, however, may lead to unnecessary treatment and resource use, as several studies have suggested that a substantial number of RA patients in sustained remission or LDA can taper or altogether stop their TNFi without experiencing a disease flare [7, 8].

Although current guidelines suggest that tapering or withdrawal of bDMARDs can be considered for patients in persistent remission [9], where persistent remission is not explicitly defined, validated predictors of successful discontinuation are needed to successfully implement practical stopping rules in daily clinical practice [10]. A number of studies have already examined predictors of successful TNFi discontinuation, but it remains a challenge to judge which patients can effectively and safely stop their TNFi without incurring a flare of the disease [11]. A recent systematic review found no consistently strong predictors for successful dose reduction or discontinuation [12]. Only shorter disease duration [13-15], less or no erosive disease [14-16], and lower disease activity [14-17] at baseline have been shown in more than one study to predict successful TNFi discontinuation. Additionally, single studies have found that younger age [14], normal body mass index (BMI) [16], non-smoking [15], anti-cyclic citrullinated peptide antibodies (ACPA) negativity [17, 18], shorter [15] or longer [19] TNFi treatment, and initial (versus delayed) TNFi treatment [13] were associated with successful TNFi discontinuation. Finally, two studies have found a tendency for more relapses among female patients $[13,17]$.

Moreover, two main types of TNFi with different mechanisms of action are used in RA: anti-TNF monoclonal antibodies versus soluble TNF receptors (receptor antagonist). Monoclonal antibody agents like adalimumab and infliximab bind specifically to TNF, while the receptor fusion protein etanercept, functioning as a decoy receptor, binds to circulating TNF and prevents it from interacting with a cell surface receptor [20-23]. Adalimumab and etanercept are currently the most frequently prescribed TNFi and generally demonstrate comparable effectiveness [24, 25]. Previous discontinuation studies, however, generally examined one specific TNFi agent only or did not examine possible differences in the predictive value of the type of TNFi (antiTNF monoclonal antibody or receptor antagonist) for successful discontinuation.
Recently, the POET trial showed that, although stopping TNFi treatment in patients with established RA in remission or with stable low disease activity resulted in substantially more flares than did continuation of TNFi, around half of the patients could successfully stop for at least 12 months [26]. The aim of the current post-hoc study was to identify baseline predictors of prolonged disease control after discontinuation of TNFi.

\section{Methods}

\section{Patients and study design}

We used data from the Dutch pragmatic POET trial, registered in the Netherlands Trial Register (NTR3112) [26]. This multicenter trial randomized RA patients with stable LDA, as measured with the 28-joint Disease Activity Score using the erythrocyte sedimentation rate (DAS28-ESR) [27], in a ratio of 2:1 to either discontinuing or continuing TNFi treatment. For those patients randomized to stopping TNFi, concomitant treatment with csDMARDs was continued. Eligible patients had to fulfill the ACR 1987 criteria for RA, be 18 years or older, and have received TNFi treatment for $\geq 1$ year. Patients also needed to have stable LDA for $\geq 6$ months before inclusion, which was operationalized as either two DAS28-ESR scores $<3.2$ or the rheumatologist's clinical judgment of remission or stable low disease activity with at least one $\mathrm{C}$-reactive protein (CRP) measurement $<10 \mathrm{mg} / \mathrm{L}$ in the last 6 months. Finally, no dosage changes were allowed to have occurred for csDMARDs or corticosteroids in the 6 months prior to inclusion.

A total of 531 patients were randomized to the stop group [26]. In case of a disease flare, defined as a DAS28ESR score $\geq 3.2$ with an increase $>0.6$ [28], the treating rheumatologist could re-initiate TNFi treatment. As the current study aimed to identify patient and clinical characteristics predictive of prolonged disease control after discontinuation of TNFi treatment, only the data from 439 patients randomized to the stop group and for whom baseline serum samples were collected to measure the multi-biomarker disease activity (MBDA) score [29] were used. Baseline characteristics were comparable between the included 439 patients with and the 92 patients without an available baseline MBDA measurement [30].

\section{Measures}

Included patients were examined by the rheumatologist and rheumatology nurse at baseline and return visits were scheduled at 3, 6, 9 and 12 months or earlier if the symptoms suggested a disease flare. The following measurements were collected at baseline: age, sex, weight, height, body mass index (BMI), disease duration, rheumatoid factor (RF) and ACPA status, erosive disease (yes/no) and medication use, including the type of TNFi (antibody vs. receptor antagonist) and concomitant csDMARD use. In a substantial subsample, the MBDA score was assessed at 
baseline. The MBDA score is a novel test that measures 12 biomarkers in serum to assess disease activity in patients with rheumatoid arthritis [29]. The scoring algorithm generates a total score from 1 to 100, with definitions for low $(<30)$, moderate (30 to 44$)$ and high $(>44)$ disease activity [31].

Standard disease activity measurements were collected at every visit and consisted of a 28-joint tender and swollen joint count (TJC28 and SJC28), laboratory measurement of the $\operatorname{ESR}(\mathrm{mm} / \mathrm{h})$ and CRP $(\mathrm{mg} / \mathrm{l})$ and a patient-reported general health assessment on a $100-\mathrm{mm}$ visual analog scale (VAS-GH). The TJC28, SJC28, ESR and VAS-GH were used to calculate the DAS28-ESR as a composite index of disease activity [27]. Physician-reported flares and medication changes were continuously recorded.

\section{Statistical analysis}

Successful discontinuation was defined as not restarting TNFi treatment within 12 months after stopping. First, univariate logistic regression analyses were performed to examine associations between potential baseline predictors and successful 12-month TNFi discontinuation. The following patient and clinical variables were considered: type of TNFi (anti-TNF monoclonal antibody (adalimumab, infliximab, golimumab or certolizumab)) vs. receptor antagonist (etanercept), concomitant csDMARD use, female sex, younger age ( $\leq 60 \mathrm{yrs}$.), shorter disease duration ( $\leq 10$ yrs.), RF negativity, ACPA negativity, nonerosive disease, normal weight $(B M I=18.5-25)$, first TNFi agent, deep remission (DAS28 $\leq 1.98)[32,33]$, and low or moderate MBDA score $(\leq 44)$ [30]. To facilitate the interpretation of odds ratios (ORs), continuous predictors were dichotomized by median split (DAS28-ESR, age, disease duration) or previously established relevant cut-off points (BMI, MBDA). ORs are classified as weak when about 1.5 , moderate when about 2.5 , strong when about 4 and very strong when about 10 [34]. Additional separate models were run to test for possible interactions between each predictor and type of TNFi. Predictors univariately associated with outcome $(P<0.10)$ were included in a multivariate logistic regression model to identify independent predictors. The multivariate model was reduced by excluding predictors from the model with $P>0.10$ (backward deletion), and the goodness of fit of the final model was estimated using the Hosmer and Lemeshow test [35], where a nonsignificant result indicates support for the model. The predictive ability of the model was examined using the area under the receiver operating characteristic (ROC) curve. All regression analyses were based on observed data. As 38 patients $(8.7 \%)$ had missing baseline values on laboratory and radiographic erosion data, the multivariate model was repeated using multiple imputation with 10 imputed datasets. Since results were very similar to non-imputed data, only the results from observed data are presented. As a sensitivity analysis, the final multivariate model was repeated using no physicianreported flare within 12 months after stopping as the dependent variable. To further explore the prognostic value of the remaining predictors, TNFi-free survival based on the number of predictors present was examined using Kaplan-Meier survival analysis. Betweengroup difference in survival was tested using the log rank test. Since MBDA testing is not common in many rheumatology practices, the multivariate and survival analyses were repeated without MBDA as a predictor. All statistical calculations were performed using SPSS 23.

\section{Results}

Table 1 summarizes the baseline characteristics of the patients $(n=439)$. Median age and disease duration was 60 and 10 years, respectively. Approximately $60 \%$ of the patients used an antibody agent, most frequently adalimumab, while $40 \%$ used etanercept. Most patients were on their first TNFi. In total, 219 (49.9\%) of the patients restarted their TNFi within 12 months, while at least one physician-reported flare was reported for 251 (57.2\%) patients. Forty-four patients with a physician-reported flare $(17.5 \%)$ did not restart their $\mathrm{TNFi}$, while no physician-reported flare was recorded for 12 patients who restarted TNFi (6.4\%).

Antibody type TNFi, shorter disease duration, nonerosiveness and low or moderate MBDA were weakly to moderately associated with successful discontinuation, defined as not restarting TNFi treatment within 12 months after stopping in univariate regression analysis (Table 2). No interactions with type of TNFi were significant and separate univariate analyses for both types of TNFi showed that the predictive value of individual variables was similar for patients discontinuing an antibody agent or etanercept. However, MBDA $\leq 44$ was significantly predictive only in patients discontinuing etanercept $(\mathrm{OR}=3.69 ; 95 \% \mathrm{CI}$ : 1.34-10.18; $P=0.012$ ) and not in patients discontinuing an antibody agent $(\mathrm{OR}=1.68$; $95 \% \mathrm{CI}: 0.81-3.45 ; P=0.162)$.

In multivariate analysis, non-erosiveness lost its significance $(\mathrm{OR}=1.34 ; 95 \% \mathrm{CI}: 0.85-2.11 ; P=0.212)$. Type of TNFi, shorter disease duration and low or moderate MBDA scores remained independently predictive of successful discontinuation, with type of TNFi being the strongest predictor (Table 3). The area under the ROC curve showed a modest predictive ability of 0.66 for these three variables. This decreased to 0.65 when omitting MBDA, suggesting rather limited added value of MBDA as a predictor for biologic-free disease control above and beyond type of TNFi and disease duration. Logistic regressions with disease duration and MBDA as 
Table 1 Baseline characteristics of the patients $(N=439)$

\begin{tabular}{|c|c|}
\hline Female, n (\%) & $296(67.4 \%)$ \\
\hline Age (yrs.), mean (SD) & $59.8(10.8)$ \\
\hline Disease duration (yrs.), median (IQR) & $10(6-17)$ \\
\hline BMI, mean (SD) & $25.9(4.3)$ \\
\hline Normal BMI (18.5-25), n (\%) & $174(39.6 \%)$ \\
\hline RF positive, $\mathrm{n}(\%)$ & $270(67.3 \%)$ \\
\hline ACPA positive, n (\%) & $277(69.1 \%)$ \\
\hline Erosive disease, n (\%) & $252(62.8 \%)$ \\
\hline ESR, median (IQR) & $9.0(5-17)$ \\
\hline TJC28, median (IQR) & $0(0-1)$ \\
\hline SJC28, median (IQR) & $0(0-0)$ \\
\hline PGA, median (IQR) & $20.7(9.0-28.1)$ \\
\hline DAS28-ESR, mean (SD) & $2.0(0.8)$ \\
\hline MBDA score, mean (SD) & $30.2(12.6)$ \\
\hline Low $(<30)$ or moderate (30-44), n (\%) & $375(85.4 \%)$ \\
\hline \multicolumn{2}{|l|}{ Type of TNFi, n (\%) } \\
\hline Etanercept & $176(40.1 \%)$ \\
\hline Adalimumab & $225(51.3 \%)$ \\
\hline Infliximab & $22(5.0 \%)$ \\
\hline Golimumab & $14(3.2 \%)$ \\
\hline Certolizumab & $2(0.5 \%)$ \\
\hline \multicolumn{2}{|l|}{ Number of TNFi, n (\%) } \\
\hline $1 \mathrm{st}$ & $379(86.5 \%)$ \\
\hline 2nd & $50(11.4 \%)$ \\
\hline $3 r d$ & $9(2.1 \%)$ \\
\hline \multicolumn{2}{|l|}{ csDMARD, n (\%) } \\
\hline Methotrexate & $362(82.5 \%)$ \\
\hline Methotrexate + glucocorticoids & $20(4.6 \%)$ \\
\hline Glucocorticoids & $6(1.4 \%)$ \\
\hline Other csDMARD & $29(6.6 \%)$ \\
\hline No DMARD & $22(5.0 \%)$ \\
\hline
\end{tabular}

TNFi tumor necrosis factor-alpha inhibitors, DAS28 disease activity score in 28 joints, $B M I$ body mass index, $R F$ rheumatoid factor, $A C P A$ anti-cyclic citrullinated peptide antibodies, ESR erythrocyte sedimentation rate, CRP Creactive protein, TJC28 28-joint tender joint count, SJC28 28-joint swollen joint count, $P G A$ patient global assessment, MBDA multi-biomarker disease activity, CSDMARD conventional synthetic disease modifying anti-rheumatic drug

continuous predictors demonstrated very similar results, with erosiveness again losing significance and type of $\mathrm{TNFi}$, shorter disease duration and lower MBDA scores remaining independently predictive of successful discontinuation [see Additional file 1].

As a sensitivity analysis, using 'no physician-reported flare' as the criterion for successful TNFi discontinuation resulted in similar findings in the total sample, with the same three predictors remaining significant in multivariate analysis. However, the predictive value of the variables tended to be slightly lower with ORs of 1.86 (95\%
Table 2 Univariate associations of baseline variables with successful TNFi discontinuation

\begin{tabular}{|c|c|c|c|}
\hline Predictor & OR & $95 \% \mathrm{Cl}$ & $P$ \\
\hline anti-TNF monoclonal antibody ${ }^{\mathrm{a}}$ & 2.26 & $1.53-3.34$ & $<0.0001$ \\
\hline Concomitant DMARD & 1.21 & $0.51-2.85$ & 0.670 \\
\hline Female sex & 1.07 & $0.72-1.60$ & 0.735 \\
\hline Younger age ( $\leq 60 \mathrm{yrs})$. & 1.17 & $0.80-1.70$ & 0.417 \\
\hline Shorter disease duration ( $\leq 10 \mathrm{yrs}$.) & 2.00 & $1.34-2.98$ & 0.001 \\
\hline RF negative & 1.14 & $0.75-1.74$ & 0.530 \\
\hline ACPA negative & 1.06 & $0.70-1.62$ & 0.775 \\
\hline Non-erosive & 1.62 & $1.08-2.44$ & 0.020 \\
\hline Normal weight (BMI 18.5-25) & 1.35 & $0.92-1.98$ & 0.128 \\
\hline First TNFi & 1.23 & $0.71-2.13$ & 0.461 \\
\hline DAS28 deep remission (DAS28 $\leq 1.98)$ & 1.21 & $0.83-1.77$ & 0.314 \\
\hline Low or moderate MBDA $(\leq 44)$ & 2.32 & $1.32-4.05$ & 0.003 \\
\hline
\end{tabular}

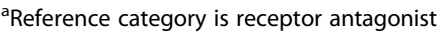

TNFi tumor necrosis factor-alpha inhibitors, csDMARD conventional synthetic disease modifying anti-rheumatic drug, $R F$ rheumatoid factor, $A C P A$ anti-cyclic citrullinated peptide, $B M I$ body mass index, DAS28 disease activity score in 28 joints, MBDA multi-biomarker disease activity

CI: $1.24-2.79 ; P=0.003), 1.78$ (95\% CI: $1.18-2.70 ; P=$ $0.006)$ and 2.49 (95\% CI: $1.35-4.59$; $\mathrm{P}=0.003)$ for antibody TNFi, shorter disease duration and low or moderate MBDA score, respectively.

TNFi-free survival was significantly different (log rank $=43.9, P<0.001)$ for patient groups based on the number of predictors present (Fig. 1). TNFi-free survival rates were $21.4 \%$ in patients with no predictor present $(n=14), 31.7 \%$ in patients with one predictor $(n=104)$, $52.6 \%$ in patients with two predictors $(n=213)$, and $66.7 \%$ in patients with three predictors $(n=108)$ present. Fairly similar results and differences between groups (log rank $=33.9, \mathrm{P}<0.001$ ) were obtained in TNFi-free survival when using only antibody type TNFi and shorter disease duration as predictors. In this analysis, TNFi-free survival rates were $32.1 \%$ in patients with no predictor present $(n=84), 48.5 \%$ in patients with one predictor $(n=231)$, and $65.3 \%$ in patients with both predictors $(n=124)$ present.

\section{Discussion}

The POET study previously demonstrated that in patients with established RA in sustained remission or with stable low disease activity, as defined by the DAS28-ESR, approximately $50 \%$ of the patients could successfully stop their TNFi for at least 12 months [26]. However, with the consequential fifty-fifty chance of relapsing, it would be helpful to identify patient and clinical predictors of prolonged disease control after discontinuation of TNFi. This post-hoc analysis showed that the type of TNFi (anti-TNF monoclonal antibody vs. receptor antagonist) being used, RA disease duration and the MBDA score at the time of 
Table 3 Multivariate associations with successful TNFi discontinuation with and without MBDA score as a predictor

\begin{tabular}{|c|c|c|c|c|c|c|}
\hline \multirow[b]{2}{*}{ Predictor } & \multicolumn{3}{|c|}{ With MBDA } & \multicolumn{3}{|c|}{ Without MBDA } \\
\hline & OR & $95 \% \mathrm{Cl}$ & P & OR & $95 \% \mathrm{Cl}$ & $P$ \\
\hline anti-TNF monoclonal antibody ${ }^{a}$ & 2.41 & $1.58-3.67$ & $<0.0001$ & 2.46 & $1.61-3.73$ & $<0.0001$ \\
\hline Disease duration < 10 yrs. & 2.15 & $1.42-3.26$ & $<0.0001$ & 2.14 & $1.42-3.23$ & $<0.0001$ \\
\hline MBDA score $\leq 44$ & 2.00 & $1.10-3.64$ & 0.023 & - & - & - \\
\hline
\end{tabular}

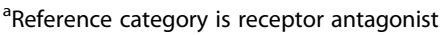

$T N F i$ tumor necrosis factor-alpha inhibitors, MBDA multi-biomarker disease activity, OR Odds ratio. Hosmer and Lemeshow with MBDA $x 2(5)=1.57, P=0.905$, area under ROC curve $=0.66(95 \% \mathrm{Cl}: 0.61-0.71, P<0.0001)$; Hosmer and Lemeshow without MBDA X2(2) $=0.00, P=1.000$, area under ROC curve $=0.65(95 \%$ Cl: $0.59-0.70, P<0.0001)$

discontinuation of TNFi were significantly associated with success of stopping. Approximately $70 \%$ of patients who were on an anti-TNF monoclonal antibody, with a disease duration of $<10$ years and a MBDA score $\leq 44$ were able to successfully stop their TNFi, while conversely $80 \%$ of patients on a TNFi receptor antagonist, with a disease duration of $\geq 10$ years and a MBDA score $>44$ restarted their TNFi within 12 months of stopping.

Several other studies have previously explored potential predictors of disease relapse after TNFi discontinuation $[11,12]$. Multiple studies found shorter disease duration, RF positivity, non-smoking, erosive disease and normal body mass index (BMI) to be predictive of successful TNFi discontinuation $[14,16]$. In the current study, shorter disease duration was also a predictor of successful discontinuation, but RF positivity and normal BMI were not. Erosive disease was univariately associated with restarting TNFi, but did not remain a unique predictor in the final multivariate model.

Higher clinical disease activity at the time of discontinuation has also previously been identified as a predictor, although results varied considerably between studies $[13,14$, 36]. In the current study, higher baseline DAS28-ESR scores were not associated with the criterion of restarting TNFi treatment within 12 months. However, a high MBDA score at the time of TNFi discontinuation was predictive of restarting TNFi. Several previous studies found that MBDA scores may be elevated when conventional clinical measures indicate remission or LDA [18, 37-39]. Furthermore, these patients were found to be at increased risk for progressive joint damage [37-39]. In patients with high baseline MBDA scores at the time of TNFi discontinuation in POET, discontinuation may have allowed a resurgence of subclinical residual inflammation and the subsequent need to restart TNFi treatment [18].

At the time of the analysis, the type of TNFi, i.e. antiTNF monoclonal antibody vs. receptor antagonist, had not been previously identified as a predictor of successful TNFi discontinuation. Very recently, however, Hashimoto et al. also found that use of infliximab, adalimumab, and golimumab, as opposed to etanercept or certolizumab pegol, was clearly more advantageous for achieving bDMARD-free remission in a retrospective registry study of patients discontinuing bDMARDs [40]. This is in line with the current findings, which also showed that patients who were using an anti-TNF monoclonal antibody (mostly adalimumab) were significantly more often able to successfully discontinue their TNFi than patients who had been using a receptor antagonist (mostly etanercept). These findings might be explained by several differences between the TNF receptor antagonists and antibodies. Firstly, TNF receptor antagonists function as decoy receptors that bind to circulating TNF, thereby mimicking the inhibitory effects of naturally occurring soluble TNF receptors, albeit with a greatly extended circulatory half-life. TNF antibodies also bind specifically to TNF and thus block its interaction with the p55 and p75 cell surface TNF receptors. However, TNF antibodies may also lyse surface TNF expressing blood cells in the presence of complement thereby possibly inducing prolonged disease control [20-23]. Secondly, pharmacokinetic properties differ between the drugs, with a single dose half-life of approximately 4 days for the TNF receptor antagonists etanercept vs. 10-20 days for the TNF antibody adalimumab [20]. Finally, there may be differences in drug dosages and dosage-intervals.

This current post-hoc analysis used a relatively large dataset collected in the POET study, a randomized controlled trial on stopping TNFi in RA patients in daily clinical practice. The subgroup of 439 patients appeared to be an unbiased sample of the total stop group. With an average age of 60 years and a median disease duration of 10 years, the sample also appeared to be representative of the population with established RA using TNFi in The Netherlands.

However, the study also has several limitations that should be considered. Besides the general limitations of exploratory post-hoc data analyses [41], one specific limitation of the current analysis is that we only focused on baseline predictors. Longitudinal (especially early) changes in variables such as the DAS28, ESR/CRP or MBDA scores could have provided insight into the potential for monitoring of these variables to predict relapse. Another possible limitation of the POET study was the decision to leave restarting of TNFi at the discretion of the treating rheumatologists. It is possible that this has led to an overestimation of successful disease control and bias in the population of TNFi restarters. Finally, due to the pragmatic nature of the POET 

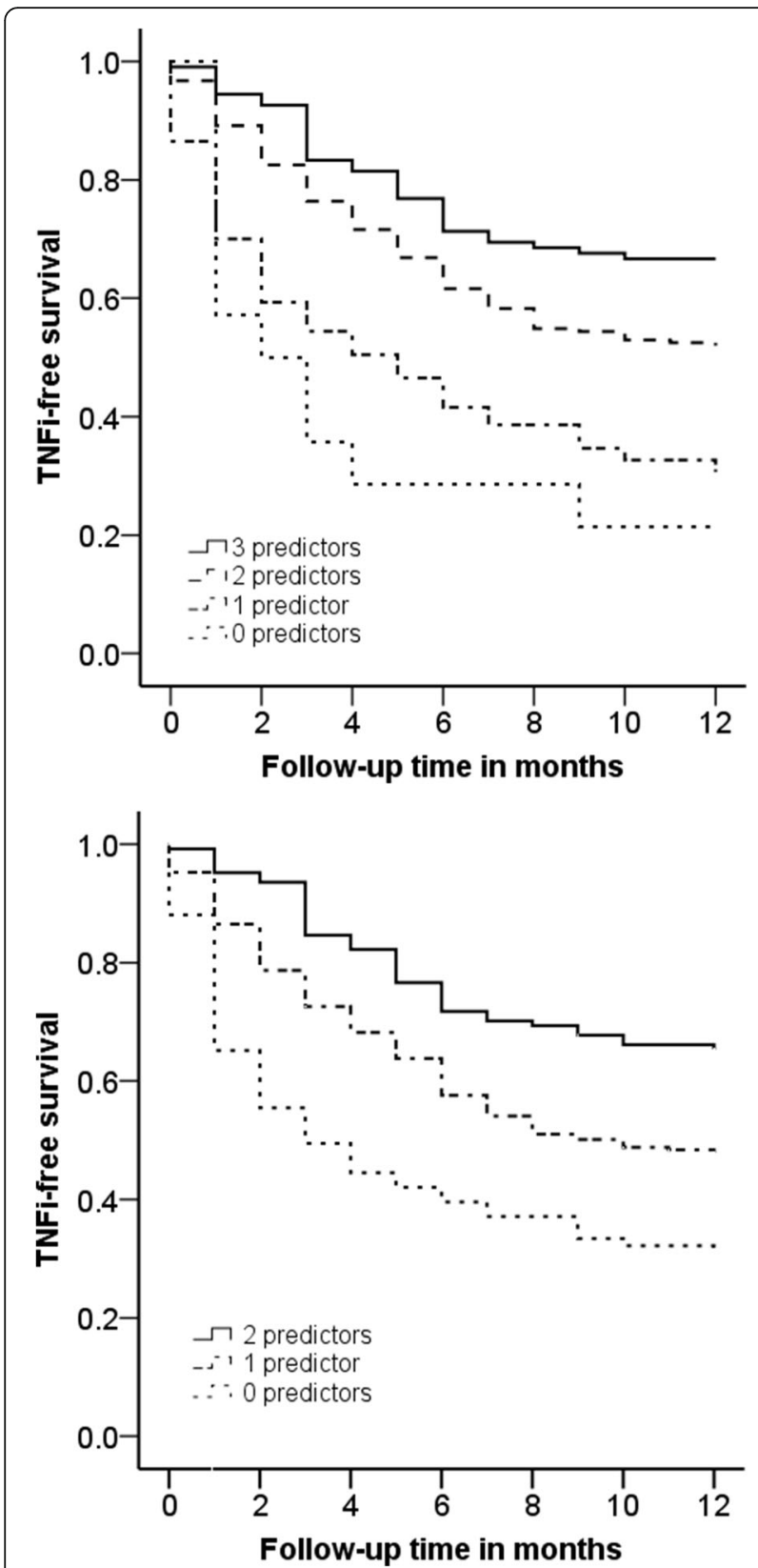

Fig. 1 Kaplan-Meier curves showing the proportion of patients not restarting TNFi per number of predictors present. Upper panel: with MBDA as predictor; Lower panel: without MBDA as predictor. MBDA = multi-biomarker disease activity

study, a small proportion of patients were still using prednisone at baseline, even though current guidelines clearly state that glucocorticoids should have been withdrawn before bDMARDs are tapered [9].

\section{Conclusions}

In patients with established RA in sustained remission or with stable LDA, use of an anti-TNF monoclonal antibody, disease duration less or equal to 10 years and low to moderate MBDA score at the time of discontinuation were significantly associated with success of stopping TNFi. Although their predictive ability was only modest, it may be useful to consider these clinical characteristics when deciding to stop TNFi treatment in RA patients in daily clinical practice. The current findings and robustness of the specific predictors should be confirmed in other samples of RA patients stopping TNFi treatment. Also, future studies could focus more on the predictive value of early changes in disease-related variables and on other potential markers for successful TNFi discontinuation.

\section{Additional file}

Additional file 1: Multivariate associations with successful TNFi discontinuation with and without MBDA score as a predictor, with disease duration and MBDA as continuous predictors. (DOCX $13 \mathrm{~kb}$ )

\section{Abbreviations}

ACPA: Anti-cyclic citrullinated peptide antibodies; bDMARD: Biological disease modifying anti-rheumatic drug; BMI: Body mass index; CRP: C-reactive protein; CSDMARD: Conventional synthetic disease modifying anti-rheumatic drug; DAS28: Disease activity score in 28 joints; DMARD: Disease modifying antirheumatic drug; ESR: Erythrocyte sedimentation rate; LDA: Low disease activity; MBDA: Multi-biomarker disease activity; OR: Odds ratio; PGA: Patient global assessment; RA: Rheumatoid arthritis; RF: Rheumatoid factor; SJC28: 28-joint swollen joint count; TJC28: 28-joint tender joint count; TNFi: Tumor necrosis factor-alpha inhibitors

\section{Acknowledgements}

The authors thank all patients, rheumatology nurses and rheumatologists of the participating centers, the members of the Steering Committee consisting of Renée Allaart (University Medical Center Leiden), Annelies Boonen (Maastricht University Medical Center), Reinhard Bos (Medical Center Leeuwarden), Liesbeth Brouwer (University Medical Center Groningen), Alfons den Broeder (Sint Maartens Clinic), Danielle Gerlag (Amsterdam Medical Center), Mieke Hazes (Erasmus University Medical Center), Willem Lems (VU Medical Center), Dirkjan van Schaardenburg (Reade), Janneke Tekstra (University Medical Center Utrecht), and Harald Vonkeman (Arthritis Center Twente MST \& University ofTwente). The authors additionally thank Gerardine Willemsen (patients association), Huib Kooiman (Dutch Ministry of Health, Welfare \& Sports), and Benien Vingerhoeds (Netherlands Organisation for Health Research and Development).

\section{Authors' contributions}

MvdL and TJ conceptualized this post-hoc study. PtK performed the statistical analysis. MGM and FLK drafted the first version of the manuscript. HV, PtK, JT, BvS, $\mathrm{RK}, \mathrm{MvO}, \mathrm{HBM}, \mathrm{HV}, \mathrm{AS}, \mathrm{MK}, \mathrm{RL}, \mathrm{PVR}, \mathrm{MvdL}$ and TJ participated in the interpretation of the results and revised the manuscript critically for important intellectual content. All authors (MGM, FLK, HV, PtK, JT, BvS, RK, MvO, HBM, HV, AS, MK, RL PvR, MvdL, TJ) read and approved the final version of the manuscript .

\section{Funding}

The POET study was funded by the Netherlands Organization for Health Research and Development (ZonMw), project number 152041002. ZonMw had no role in the study design, data collection and analysis, decision to publish, or preparation of the manuscript. Crescendo Bioscience funded the shipping of serum samples to its laboratory and the generation of biomarker data, but did not have any role in the study design, data collection or decision to publish the manuscript.

\section{Availability of data and materials}

The datasets generated and analyzed for the current study are not publicly available due to legal restrictions related to data privacy protection. However, the data are available upon reasonable request to all interested researchers after authorization of the POET steering committee. Researchers interested in data 
access may contact the PI of the POET study Tim L. Jansen (tjansen@viecuri.nl) to apply for access.

\section{Ethics approval and consent to participate}

Ethical approval for the study was granted by the Committee on Research involving Human Subjects, region Arnhem-Nijmegen (CCMO number: NL36793.091.11) and local feasibility and approval was confirmed by the ethical review boards of all participating hospitals. All participants provided written informed consent.

\section{Consent for publication}

Not applicable.

\section{Competing interests}

The authors declare that they have no competing interests.

\section{Author details}

'Department of Rheumatology, Medisch Spectrum Twente, Enschede, The Netherlands. ${ }^{2}$ Department of Psychology, Health \& Technology, University of Twente, PO BOX 217, 7500 AE Enschede, the Netherlands. ${ }^{3}$ Department of Rheumatology, Radboud University Medical Center, Nijmegen, The Netherlands. ${ }^{4}$ Department of Rheumatology, University Medical Center Utrecht, Utrecht, The Netherlands. ${ }^{5}$ Department of Rheumatology, Albert Schweitzer Hospital, Dordrecht, The Netherlands. ${ }^{6}$ Department of Rheumatology, Meander Medical Centre, Amersfoort, The Netherlands. ${ }^{7}$ Department of Clinical Immunology and Rheumatology, Academic Medical Center, Amsterdam, The Netherlands. ${ }^{8}$ Department of Rheumatology, Ziekenhuis Groep Twente, Hengelo, The Netherlands. ${ }^{9}$ Department of Rheumatology, Rijnstate, Arnhem, The Netherlands. ${ }^{10}$ Department of Rheumatology, Medical Centre Leeuwarden, Leeuwarden, The Netherlands. ${ }^{11}$ Department of Rheumatology and Clinical Immunology, Maasstad Hospital, Rotterdam, The Netherlands. ${ }^{12}$ Department of IQ Healthcare, Radboud University Medical Center, Nijmegen, The Netherlands. ${ }^{13}$ Department of Rheumatology, VieCuri Medical Center, Venlo, The Netherlands.

Received: 12 September 2018 Accepted: 31 May 2019

Published online: 13 June 2019

\section{References}

1. van Vollenhoven RF. Treatment of rheumatoid arthritis: state of the art 2009. Nat Rev Rheumatol. 2009:5:531-41.

2. Mclnnes IB, O'Dell JR. State-of-the-art: rheumatoid arthritis. Ann Rheum Dis 2010:69:1898-906.

3. Mahajan TD, Mikuls TR. Recent advances in the treatment of rheumatoid arthritis. Curr Opin Rheumatol. 2018;30:231-7.

4. Chen Y-F, Jobanputra P, Barton P, Jowett S, Bryan S, Clark W, et al. A systematic review of the effectiveness of adalimumab, etanercept and infliximab for the treatment of rheumatoid arthritis in adults and an economic evaluation of their cost-effectiveness. Health Technol Assess. 2006;10:1-229.

5. Wiens A, Venson R, Correr CJ, Otuki MF, Pontarolo R. Meta-analysis of the efficacy and safety of adalimumab, etanercept, and infliximab for the treatment of rheumatoid arthritis. Pharmacotherapy. 2010;30:339-53.

6. Nam JL, Takase-Minegishi K, Ramiro S, Chatzidionysiou K, Smolen JS, van de Heijde D, et al. Efficacy of biological disease-modifying antirheumatic drugs: a systematic literature review informing the 2016 update of the EULAR recommendations for the management of rheumatoid arthritis. Ann Rheum Dis. 2017:76:1113-36.

7. Tanaka Y. Intensive treatment and treatment holiday of TNF-inhibitors in rheumatoid arthritis. Curr Opin Rheumatol. 2012;24:319-26.

8. Tanaka Y. Next stage of RA treatment: is TNF inhibitor-free remission a possible treatment goal? Ann Rheum Dis. 2013;72(Suppl 2):ii124-7.

9. Smolen JS, Landewé R, Breedveld FC, Buch M, Burmester G, Dougados M, et al. EULAR recommendations for the management of rheumatoid arthritis with synthetic and biological disease-modifying antirheumatic drugs: 2013 update. Ann Rheum Dis. 2014;73:492-509.

10. van Ingen ILA, Lamers-Karnebeek F, Jansen TL. Optimizing the expediency of TNFi in rheumatoid arthritis: offering a TNFi holiday in patients having reached low-disease activity in the maintenance phase. Expert Opin Biol Ther. 2014;14:1761-7.
11. van den Broek M, Visser K, Allaart CF, Huizinga TWJ. Personalized medicine: predicting responses to therapy in patients with RA. Curr Opin Pharmacol. 2013;13:463-9.

12. Tweehuysen $\mathrm{L}$, van den Ende $\mathrm{CH}$, Beeren FMM, Been EMJ, van den Hoogen FHJ, den Broeder AA. Little evidence for usefulness of biomarkers for predicting successful dose reduction or discontinuation of a biologic agent in rheumatoid arthritis: a systematic review. Arthritis Rheumatol. 2017;69:301-8.

13. Saleem B, Keen H, Goeb V, Parmar R, Nizam S, Hensor EMA, et al. Patients with RA in remission on TNF blockers: when and in whom can TNF blocker therapy be stopped? Ann Rheum Dis. 2010;69:1636-42.

14. Tanaka Y, Takeuchi T, Mimori T, Saito K, Nawata M, Kameda H, et al. Discontinuation of infliximab after attaining low disease activity in patients with rheumatoid arthritis: RRR (remission induction by Remicade in RA) study. Ann Rheum Dis. 2010;69:1286-91.

15. van den Broek M, Klarenbeek NB, Dirven L, van Schaardenburg D, Hulsmans HMJ, Kerstens PJSM, et al. Discontinuation of infliximab and potential predictors of persistent low disease activity in patients with early rheumatoid arthritis and disease activity score-steered therapy: subanalysis of the BeSt study. Ann Rheum Dis. 2011;70:1389-94.

16. Kavanaugh A, Lee SJ, Curtis JR, Greenberg JD, Kremer JM, Soto L, et al. Discontinuation of tumour necrosis factor inhibitors in patients with rheumatoid arthritis in low-disease activity: persistent benefits. Data from the Corrona registry. Ann Rheum Dis. 2015;7:1150-5.

17. Haschka J, Englbrecht M, Hueber AJ, Manger B, Kleyer A, Reiser M, et al. Relapse rates in patients with rheumatoid arthritis in stable remission tapering or stopping antirheumatic therapy: interim results from the prospective randomised controlled RETRO study. Ann Rheum Dis. 2016;75:45-51.

18. Rech J, Hueber AJ, Finzel S, Englbrecht M, Haschka J, Manger B, et al. Prediction of disease relapses by multibiomarker disease activity and autoantibody status in patients with rheumatoid arthritis on tapering DMARD treatment. Ann Rheum Dis. 2015;75:1637-44

19. Brocq O, Millasseau E, Albert C, Grisot C, Flory P, Roux C-H, et al. Effect of discontinuing TNFalpha antagonist therapy in patients with remission of rheumatoid arthritis. Jt Bone Spine. 2009:76:350-5.

20. Tracey D, Klareskog L, Sasso EH, Salfeld JG, Tak PP. Tumor necrosis factor antagonist mechanisms of action: a comprehensive review. Pharmacol Ther. 2008;117:244-79.

21. Arora T, Padaki R, Liu L, Hamburger AE, Ellison AR, Stevens SR, et al. Differences in binding and effector functions between classes of TNF antagonists. Cytokine. 2009;45:124-31.

22. Silva LCR, Ortigosa LCM, Benard G. Anti-TNF-a agents in the treatment of immune-mediated inflammatory diseases: mechanisms of action and pitfalls. Immunotherapy. 2010;2:817-33.

23. Marotte $\mathrm{H}$, Cimaz R. Etanercept - TNF receptor and IgG1 fc fusion protein: is it different from other TNF blockers? Expert Opin Biol Ther. 2014:14:569-72.

24. Kievit W, Adang EM, Fransen J, Kuper HH. Van de Laar M a FJ, Jansen TL, et al. the effectiveness and medication costs of three anti-tumour necrosis factor alpha agents in the treatment of rheumatoid arthritis from prospective clinical practice data. Ann Rheum Dis. 2008;67:1229-34.

25. Singh JA, Christensen R, Wells GA, Suarez-Almazor ME, Buchbinder R, LopezOlivo MA, et al. Biologics for rheumatoid arthritis: an overview of Cochrane reviews. Cochrane Database Syst Rev. 2009;4:CD007848.

26. Ghiti Moghadam M, Vonkeman HE, Ten Klooster PM, Tekstra J, van Schaardenburg D, Starmans-Kool M, et al. Stopping Tumor Necrosis Factor Inhibitor Treatment in Patients With Established Rheumatoid Arthritis in Remission or With Stable Low Disease Activity: A Pragmatic Multicenter, Open-Label Randomized Controlled Trial. Arthritis Rheumatol (Hoboken, NJ). 2016;68:1810-7.

27. Prevoo ML, van 't Hof MA, Kuper HH, van Leeuwen MA, van de Putte LB, van Riel PL. Modified Disease Activity Scores that include twenty-eight-joint counts: development and validation in a prospective longitudinal study of patients with rheumatoid arthritis. Arthritis Rheum. 1995;38:44-8.

28. van der Maas A, Lie E, Christensen R, Choy E, de Man YA, van Riel P, et al. Construct and criterion validity of several proposed DAS28-based rheumatoid arthritis flare criteria: an OMERACT cohort validation study. Ann Rheum Dis. 2013;72:1800-5.

29. Centola M, Cavet G, Shen Y, Ramanujan S, Knowlton N, Swan KA, et al. Development of a multi-biomarker disease activity test for rheumatoid arthritis. PLoS One. 2013;8:e60635.

30. Ghiti Moghadam M, Lamers-Karnebeek FBG, Vonkeman HE, ten Klooster PM, Tekstra J, Schilder AM, et al. Multi-biomarker disease activity score as a predictor of disease relapse in patients with rheumatoid arthritis stopping 
TNF inhibitor treatment. PLoS One. 2018;13:e0192425. https://doi.org/10. 1371/journal.pone.0192425.

31. Curtis JR, van der Helm-van Mil AH, Knevel R, Huizinga TW, Haney DJ, Shen $Y$, et al. Validation of a novel multibiomarker test to assess rheumatoid arthritis disease activity. Arthritis Care Res (Hoboken). 2012;64:1794-803.

32. Tanaka Y, Hirata S, Kubo S, Fukuyo S, Hanami K, Sawamukai N, et al. Discontinuation of adalimumab after achieving remission in patients with established rheumatoid arthritis: 1-year outcome of the HONOR study. Ann Rheum Dis. 2015;74:389-95.

33. Tanaka Y, Smolen J, Jones H, Szumski A, Marshall L, Emery P. Baseline characteristics and treatment outcomes of patients who achieve deep remission in rheumatoid arthritis. Ann Rheum Dis. 2016;75(Suppl 2):188.2-189.

34. Rosenthal JA. Qualitative descriptors of strength of association and effect size. J Soc Serv Res. 1996;21:37-59.

35. Hosmer DW, Lemeshow S. Applied logistic regression. 2nd ed. New York, NY: John Wiley \& Sons, Inc:; 2000.

36. Harigai M, Takeuchi T, Tanaka Y, Matsubara T, Yamanaka H, Miyasaka N. Discontinuation of adalimumab treatment in rheumatoid arthritis patients after achieving low disease activity. Mod Rheumatol. 2012;22:814-22.

37. van der Helm-van Mil AHM, Knevel R, Cavet G, Huizinga TWJ, Haney DJ. An evaluation of molecular and clinical remission in rheumatoid arthritis by assessing radiographic progression. Rheumatology (Oxford). 2013;52:839-46.

38. Hambardzumyan K, Bolce R, Saevarsdottir S, Cruickshank SE, Sasso EH, Chernoff $D$, et al. Pretreatment multi-biomarker disease activity score and radiographic progression in early RA: results from the SWEFOT trial. Ann Rheum Dis. 2015;74:1102-9.

39. Li W, Sasso EH, van der Helm-van Mil AHM, Huizinga TWJ. Relationship of multi-biomarker disease activity score and other risk factors with radiographic progression in an observational study of patients with rheumatoid arthritis. Rheumatology (Oxford). 2016;55:357-66.

40. Hashimoto M, Furu M, Yamamoto W, Fujimura T, Hara R, Katayama M, et al. Factors associated with the achievement of biological disease-modifying antirheumatic drug-free remission in rheumatoid arthritis: the ANSWER cohort study. Arthritis Res Ther. 2018;20:165.

41. Curran-Everett D, Milgrom H. Post-hoc data analysis. Curr Opin Allergy Clin Immunol. 2013;13:223-4.

\section{Publisher's Note}

Springer Nature remains neutral with regard to jurisdictional claims in published maps and institutional affiliations.

Ready to submit your research? Choose BMC and benefit from:

- fast, convenient online submission

- thorough peer review by experienced researchers in your field

- rapid publication on acceptance

- support for research data, including large and complex data types

- gold Open Access which fosters wider collaboration and increased citations

- maximum visibility for your research: over $100 \mathrm{M}$ website views per year

At $\mathrm{BMC}$, research is always in progress.

Learn more biomedcentral.com/submissions 